\title{
Supramolecular Glow-Sticks
}

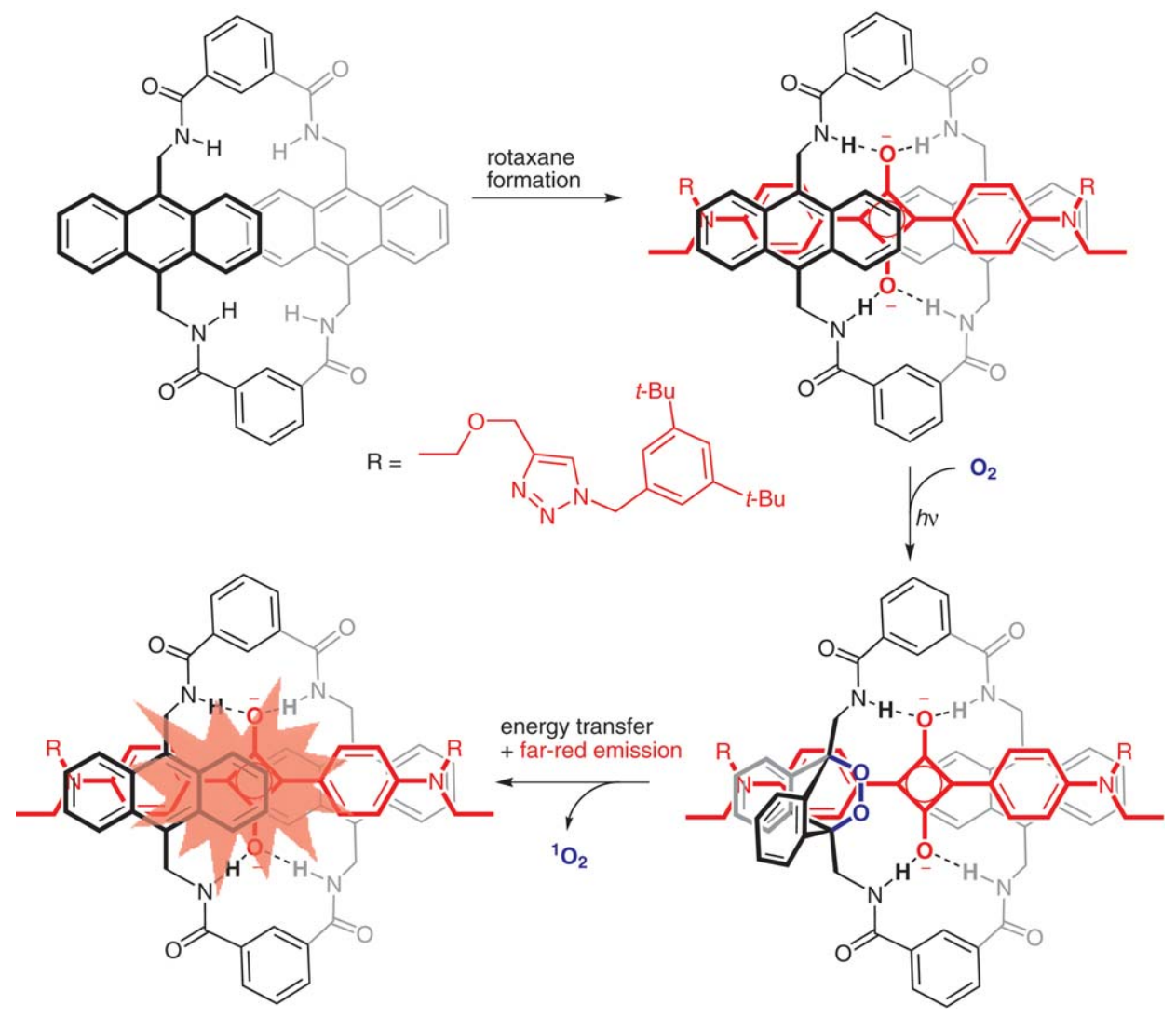

Key words

fluorescence

rotaxanes

host-guest systems

Significance: This group has previously demonstrated the formation of rotaxanes of far-red (nearinfrared) emitting squaraine dyes as a method for creating highly emissive functional materials for biological applications. The emission at ca. $750 \mathrm{~nm}$ is in the range where biological tissues have reasonable transparency. The chemiluminescent nature of these dyes and the absence of background can enable imaging with single-photon counting methods.
Comment: The formation of the anthracene peroxide complex and the thermal elimination to produce photons is an elegant method for creating an imaging agent. The ability to functionalize the macrocycle and the squaraine guest can be used to create selective contrast, and there are exciting prospects for biological imaging with the supramolecular devices. 